\title{
Inter-sector GDP Substitutability in Macro-Money Demand: Novel Evidence for India
}

\author{
Subrahmanyam Ganti*, Debashis Acharya \\ School of Economics, University of Hyderabad, India
}

Copyright $(2017$ by authors, all rights reserved. Authors agree that this article remains permanently open access under the terms of the Creative Commons Attribution License 4.0 International License

\begin{abstract}
The gross domestic product (GDP) as a scale variable in the macro-money demand function is justified only on the simplifying but verifiable assumption that the individual-sector GDPs have the same marginal money demand propensities. This assumption is easily verifiable by replacing the aggregate GDP with the services sector and commodity sector GDPs as two scale variables. The money demand propensities differ between these two sectors. To empirically verify this, a variable elasticity of substitution model is posited with these two sector GDPs as scale variables. This novel model permits us to estimate the parameter of elasticity of substitution between the two-sector GDPs.We expect the elasticity estimate to be greater than unity first and decrease towards unity later in the post-liberalization period 1992-2012 and this ensures a unitary income elasticity of demand for money for the aggregate GDP. For the pre-liberalization period (1971 to 1991) we expect the substitutability between the two sectors to be either less than unity or even negative. The policy implication of disparate sector-GDP growth rates for money demand should not be ignored in an emerging economy of India, where the GDP structure evolves towards invariance as in a developing economy.
\end{abstract}

\section{Keywords Intersector GDP Substitutability,} Macro-money Demand Function, 'Transcendental' Functional Specification

"Truth is never absolute because the basis of truth is a hypothesis".

--Anonymous

\section{Introduction}

\subsection{Why a New Money Demand Study Again}

It is well known that in a structurally evolving emerging market economy, inter-sector interactions may create disparate money-demand propensities and they are likely to create significant influence on the macro-money demand function. These very disparate sector money demand propensities can be identified in three different ways; Firstly, changes in the sector composition - concentration or diversification - can show up as bias in the macro-money demand function [Ganti, 1996 and 2002] Secondly, these can end up as stored up information hidden behind the income elasticity of money demand [Ganti and Bhamidipati, 2011]; and [Ganti, Telidevara and Acharya, 2016]. Thirdly, these can also create substitutability or complementarity between the sectors so far as the demand for money is concerned. The rest of the study is organized as follows: Section 2 provides brief explanation as to why distinguish between commodities and services for studying macro-money demand; section3 posits a variable elasticity of substitution model of money demand and derives the elasticity of substitution formulae between commodities and services; section 4 presents a discussion of the regression results and section 5 concludes with a summary and remarks.

\section{Why Distinguish between Commodities and Services}

Commodities are fungible and services are intangible. Commodities are off-the-shelf offerings and much easier to bid price. A bid is essentially a pricing quote for a known item .On the other hand a service is a 'proposal', consisting mainly, not only of identifying what needs to be delivered but also as to how that will be done. This is as it should be because the explanation is as important as the price. In case of a commodity, one knows from the outset, what needs to be delivered. In case of a service it, often, turns out to be a proposal or a solution as to what will be delivered as line items and also pricing them. Although experiences count with respect to both, those with services are more unique than those with commodities, because an experience is as real an offering as any commodity. In this sense, experiences are memorable too. Thus, the progression of pricing value from commodities to services is a journey from the impersonal market transactions to entirely personal and unique transactions. The distinction between goods and services has gained much more significance for predicting core inflation [Peach, Rich and Linder, 2013]. 


\section{The Two Sector Model}

Most econometric studies excluding those by [Ganti, 1996 and Ganti et al., 2016] relating to the macro-money demand function estimation have relied upon the GDP as the scale variable and interest rate as the opportunity cost variable in the specification. Our novel model posits the very well known 'transcendental' functional specification as in (1) below [Knox Lowell, 1968]. It not only allows the scale $(\alpha+\beta)$ exponents of $y_{1}$ and $y_{2}$ in (1)) to vary, but also the elasticity of substitution $(\sigma)$ as in (5) below to vary over time. The sum of exponents of $y_{1}$ and $y_{2}$ here constitute the counterpart of ' $m$ ' elasticity with respect to real GDP in the standard macro-money demand function. Thus, in our function (1) the real GDP elasticity of ' $m$ ' can be greater than/ equal to/ or less than unity. Also, if is ' $\gamma$ ' zero, then our transcendental function reduces to the simple Cobb-Douglas specification. There is no constraint placed upon the sign of ' $\gamma$ '.

$$
m=A y_{1}^{\alpha} y_{2}^{\beta} \exp \left(\gamma \frac{y_{1}}{y_{2}}-\theta_{i}\right)
$$

Where, $\mathrm{m}=\mathrm{M} / \mathrm{P}$ is real money (nominal money supply deflated by the GDP deflator) $\mathrm{y}_{1}=$ the real output in the commodity sector $\left(y_{1} / p 1\right)$ and $y_{2}$, the real output of the services sector $\left(y_{2} / p 2\right)$. The marginal increase in the real money demand with respect to an increase in the real output of commodities $\mathrm{y}_{1}$ is:

$$
\begin{aligned}
\frac{\partial m}{\partial y_{1}}=A \alpha y_{1}^{\alpha-1} y_{2}^{\beta} \exp \left(\gamma \frac{y_{1}}{y_{2}}-\theta_{i}\right)+A y_{1}^{\alpha} y_{2}^{\beta} \exp \left(\gamma \frac{y_{1}}{y_{2}}-\theta_{i}\right)\left(\frac{\gamma}{y_{2}}\right) \\
=A y_{1}^{\alpha} y_{2}^{\beta} \exp \left(\gamma \frac{y_{1}}{y_{2}}-\theta_{i}\right)\left(\frac{\alpha}{y_{1}}+\frac{\gamma}{y_{2}}\right) \\
=m\left(\frac{\alpha}{y_{1}}+\frac{1}{y_{2}}\right) \\
=m\left(\frac{\alpha y_{2}+\gamma y_{1}}{y_{1} y_{2}}\right)
\end{aligned}
$$

Similarly for real services output $\mathrm{y}_{2}$ the marginal increase in the real money demand is:

$$
\begin{aligned}
\frac{\partial m}{\partial y_{2}}=A \beta y_{1}^{\alpha} y_{2}^{\beta-1} & \exp \left(\gamma \frac{y_{1}}{y_{2}}-\theta_{i}\right)-A y_{1}^{\alpha} y_{2}^{\beta} \exp \left(\gamma \frac{y_{1}}{y_{2}}-\theta_{i}\right)\left(\frac{\gamma y_{1}}{y_{2}}\right) \\
= & A y_{1}^{\alpha} y_{2}^{\beta} \exp \left(\gamma \frac{y_{1}}{y_{2}}-\theta_{i}\right)\left(\frac{\beta}{y_{1}}+\frac{\gamma y_{1}}{y_{2}}\right) \\
= & m\left(\frac{\beta y_{2}-\gamma y_{1}}{y_{2}^{2}}\right)
\end{aligned}
$$

The Marginal rate of Substitution (MRS) between commodities and services from (2) and (3) is:

$$
\begin{aligned}
\frac{d y_{1}}{d y_{2}}=\frac{\frac{d m}{d y_{2}}}{\frac{d m}{d y_{1}}} & =-\left(\frac{\beta y_{2}-\gamma y_{1}}{y_{2}^{2}}\right)\left(\frac{y_{1} y_{2}}{\alpha y_{2}+\gamma y_{1}}\right) \\
& =-\left(\frac{\beta-\frac{y \gamma_{1}}{y_{2}}}{\alpha+\frac{\gamma y_{1}}{y_{2}}}\right)\left(\frac{y_{1}}{y_{2}}\right)=-\frac{\beta-\gamma x}{\alpha+\gamma x} x
\end{aligned}
$$

Where $x=\frac{y 1}{y 2}$. An increase in the ratio of $x=\frac{y 1}{y 2}$ will lead to decrease in MRS only if $\beta>\gamma x$. TheElasticity of substitution between commodity and services outputs is

$$
\sigma_{12}=\frac{d \ln \left(\frac{y_{1}}{y_{2}}\right)}{d \ln (M R S)}=\frac{\left(\frac{\Delta x}{x}\right)}{\frac{\Delta M R S}{M R S}}=\frac{(\alpha+\gamma x)(\beta-\gamma x)}{\alpha \beta-2 \alpha \gamma x-\gamma^{2} x^{2}}
$$

Tables 1 and 2 present the results for the regression equation (7) which is the log-linear version of (6):

$$
\left(\frac{M_{1}}{P}\right)=\left(\frac{\text { commodity-gdp }}{P}\right)^{\alpha}\left(\frac{\text { services-gdp }}{P}\right)^{\beta} \exp ^{\left(\gamma \frac{\text { commodity-gdp }}{\text { services-gdp }}\right)-\theta_{i}}
$$

Or alternatively,

$$
\ln \left(\frac{M_{1}}{P}\right)=\beta_{0}+\alpha\left(\frac{\text { commodity }-g d p}{P}\right)+\beta \ln \left(\frac{\text { services }-g d p}{P}\right)+\gamma\left(\frac{\text { commodity }-g d p}{\text { service }-g d p}\right)+\theta_{i}+\epsilon
$$




\section{Econometric Results of (7)}

Table 1 presents the OLS estimates of (7). For the opportunity cost variable we have used the one year deposit rate of interest. We experimented with the call money rate of the interbank market also. In view of very similar results and hence to save space, we have not reported them here. The OLS results are adjusted for first order autocorrelation of the residuals. The estimation of equation (7) refers to the post-liberalization period only and the time period covers 1992-2012. The parameter estimates of (7) clearly suggest that the transcendental function is more meaningful than the standard macro-money demand function in view of the GDP-structure change of the emerging Indian market economy. The sum of the exponents of the scale variables clearly tells us that the aggregate income elasticity of money demand is greater than unity. The negative but not significant- at- all estimate of the log (real commodity GDP) variable suggests that the distinction we have made in the GDP structure is relevant. Further, the positive but significant parameter estimates of the opportunity- cost variable (one year deposit rate) though a contradiction of the conventional negative sign need not be so in the Indian context. In separate studies [Ganti, 1997-98; Ganti, Telidevara and Acharya, 2014 and Ganti and Jangili, 2017] the empirical evidence suggests the presence of a perverse liquidity effect of the opportunity cost variable in the Indian economy.

Table 4.1. Regression Results of (7) (One-year Deposit Rate)

\begin{tabular}{|c|c|c|c|c|}
\hline & $1992-2012$ & $1970-1991$ & & \\
\hline $\begin{array}{c}\text { log(Real } \\
\text { Commodity GDP) }\end{array}$ & -1.633 & 1.043 & -1.739 & 1.452 \\
\hline $\begin{array}{c}\text { log (Real Services } \\
\text { GDP) }\end{array}$ & $3.115^{\prime \prime}$ & 0.856 & 2.055 & 1.445 \\
\hline $\begin{array}{c}\text { Commodity to } \\
\text { Services GDP ratio }\end{array}$ & $2.560^{\prime \prime}$ & 1.280 & 1.279 & 1.161 \\
\hline Deposit rate & $1.064 "$ & 0.536 & -0.883 & 0.690 \\
\hline constant & -7.907 & 1.737 & 49.072 & 12.345 \\
\hline $\begin{array}{c}\text { Number of } \\
\text { observations }\end{array}$ & 20 & & 22 & \\
\hline Log-Likelihood & 44.40 & & 39.06 & \\
\hline rho & 0.901 & & 0.999 & \\
\hline dw 0 & 1.268 & & 1.592 & \\
\hline $\mathrm{dw}$ & 1.971 & & 2.094 & \\
\hline $\mathrm{R}^{2}$ & 0.832 & & 0.237 & \\
\hline Adjusted $\mathrm{R}^{2}$ & 0.784 & & 0.047 & \\
\hline
\end{tabular}

Note: $\mathrm{xxx}=$ significant at or better than $1 \% ; \mathrm{xx}=$ significant at $5 \%$ or better

\subsection{The MRS and the Elasticity of Substitution Estimates}

Using the parameter estimates from Table 4.1 and the formulae (4) and (5) we reported the MRS and the Elasticity of Substitution (a) estimates in Table 4.2 below. It is clear from the time series of estimates of both the MRS and the elasticity both are decreasing over the time period 1992-2012. This is as they should be for the simple reason that the GDP structure is maturing towards a dominant services sector. As a result the elasticity of substitution converges to unity and the estimates reveal this trend. This can be easily verified by a simple regression of the elasticity on time as reported below (A):

Table 4.2. MRS and Substitution Elasticity Estimates (Deposit Rate: 192-2012)

\begin{tabular}{|c|c|c|}
\hline Year & MRS & Elasticity \\
\hline $1992-93$ & 3.3045 & 1.2450 \\
\hline 1993-94 & 3.2662 & 1.2422 \\
\hline 1994-95 & 3.2985 & 1.2446 \\
\hline 1995-96 & 3.1908 & 1,2366 \\
\hline 1996-97 & 3.2410 & 1.2403 \\
\hline 1997-98 & 3.0099 & 1.2231 \\
\hline 1998-99 & 2.9404 & 1.2179 \\
\hline 1999-00 & 2.7859 & 1.2063 \\
\hline 2000-01 & 2.7273 & 1.2019 \\
\hline 2001-02 & 2.6763 & 1.1981 \\
\hline 2002-03 & 2.5211 & 1.1864 \\
\hline 2003-04 & 2.4967 & 1.1845 \\
\hline 2004-05 & 2.3941 & 1.1768 \\
\hline 2005-06 & 2.3159 & 1.1709 \\
\hline 2006-07 & 2.2913 & 1.1690 \\
\hline 2007-08 & 2.2439 & 1.1654 \\
\hline 2008-09 & 2.1181 & 1.1559 \\
\hline 2009-10 & 2.0518 & 1.1509 \\
\hline 2010-11 & 2.0290 & 1.1492 \\
\hline 2011-12 & 1.9501 & 1.1432 \\
\hline
\end{tabular}

Note: MRS $=$ Marginal rate of substitution of $\mathrm{y}_{1}$ and $\mathrm{y}_{2}$; Elasticity $=$ Elasticity of substitution between $\mathrm{y}_{1}$ and $\mathrm{y}_{2}$

(A) Elasticity a $=1.257-0.0059$.time; Adjusted R-square= $0.9831 ; \mathrm{F}=1107.8$

t-value(594.0) (-33.3) 1992-2012

It is clear from (A) that the elasticity estimate is not only showing declining trend, but also converging towards the unity value which is the intercept estimate 1.257 . Though the estimate is significantly different from unity, it is closer to unity as it is supposed to be for a maturing GDP structure of an emerging economy of India. This feature is further verified and supported by the increasing trend in elasticity estimates for the earlier highly regulated economy of India. In fact, substitutability between the two sectors would be close to negligible. In an otherwise largely barter economy of India, especially of the large agricultural sector, zero substitutability between the two broad sectors becomes a reality. Monetization of an erstwhile barter economy alone can lead to release of otherwise barter- tied resources into a market economy and hence inter-sector interactions through 
monetary exchanges and then substitutability between the sectors [Ganti and Cosimano, 1979]. Regression of the elasticity on time for the period 1970-1991 reported in (B) below vindicates our assertion:

(B) Elasticity $\sigma=-0.0862+0.0256$.time; Adjusted $\mathrm{R}$-square $=0.9135 ; \mathrm{F}=222.9$

t-value $\quad(-3.827)(14.93)$

1970-1991

Table 4.3. MRS and Substitution Elasticity estimates (Deposit Rate: 1970-1991)

\begin{tabular}{|c|c|c|}
\hline Year & MRS & Elasticity \\
\hline $1970-71$ & -5.7085 & -0.0286 \\
\hline $1971-72$ & -209.9733 & -0.0012 \\
\hline $1972-73$ & 6.0549 & 0.0619 \\
\hline 1973-74 & 46.8710 & 0.0056 \\
\hline $1974-75$ & 8.2972 & 0.0403 \\
\hline $1975-76$ & 20.3892 & 0.0137 \\
\hline $1976-77$ & 4.1003 & 0.1109 \\
\hline $1977-78$ & 5.4848 & 0.0713 \\
\hline 1978-79 & 5.4531 & 0.0719 \\
\hline $1979-80$ & 2.5341 & 0.2472 \\
\hline $1980-81$ & 2.8862 & 0.1981 \\
\hline $1981-82$ & 3.0122 & 0.1842 \\
\hline $1982-83$ & 2.5918 & 0.2379 \\
\hline $1983-84$ & 3.1025 & 0.1752 \\
\hline 1984-85 & 2.6648 & 0.2269 \\
\hline $1985-86$ & 2.1742 & 0.3195 \\
\hline $1986-87$ & 1.9224 & 0.3885 \\
\hline $1987-88$ & 1.7109 & 0.4602 \\
\hline $1988-89$ & 1.9638 & 0.3759 \\
\hline $1989-90$ & 1.7697 & 0.4390 \\
\hline $1990-91$ & 1.7214 & 0.4563 \\
\hline $1991-92$ & 1.5397 & 0.5273 \\
\hline
\end{tabular}

Note: MRS $=$ Marginal Rate of Substitution of $\mathrm{y}_{1}$ and $\mathrm{y}_{2}$; Elasticity $=$ Elasticity of Substitution between $\mathrm{y}_{1}$ and $\mathrm{y}_{2}$

\section{Some Concluding Remarks}

Most macroeconomic money demand studies deploy the standard macro-money demand specification with GDP as the scale variable and an interest rate as the opportunity cost variable. For an evolving GDP sector structure and a gradual financial liberalization of an emerging market economy, the standard macro-money demand specification provides a biased function for monetary policy guidance. This happens to hold for the Indian economy as India is an emerging market economy. The first author of this study has verified this empirically in several reported studies published earlier in the Indian and in international journals.

The present study deploys a 'transcendental' functional specification for the macro-money demand function with the commodities and services sectors as scale variables in place of the total GDP as the single scale variable. One year deposit rate is used as the opportunity cost variable. The nature of the transcendental specification is such that it enables us to verify the substitutability between the two scale variables in so far as the money demand is concerned. This is done by the time series estimates of the variable elasticity of substitution between $\mathrm{y}_{1}$ and $\mathrm{y}_{2}$ for the post (1992-2012) and pre-liberalization (1970-1991) periods. Further, the regression results provide empirical evidence in support of our assertion that the Indian economy is evolving towards a mature economy with one-to-one substitutability between the two sectors. At that mature stage, the standard macro-money demand function comes back into its own, unbiased, as a meaningful monetary policy framework.

One distinct direction of future research is to include electronic money in the money supply. Then the aggregate GDP elasticity of money demand may exceed unity even for an advanced economy with different policy implications.

\section{Acknowledgements}

The authors gratefully acknowledge the computational help of Dr. Sridhar Telidevara, Associate Professor, DMI, Gurgaon Campus, Gurgaon. India. However, the authors remain responsible for any errors.

\section{REFERENCES}

[1] Gnti. Subrahmanyam, 1996, "Economic Sectoral Bias in Macro-Money Demand Function for India: Some Evidence", Journal of Economic and Social Measurement, 22(December, USA), pp.219-230.

[2] Ganti Subrahmanyam, 2002, "Some Potential Biases in the Standard Money Demand Function, for India",Pp. 303-316, in Indian Economy:Agenda for the 21st Century: Essays in Honour of P R Brahmananda, edited by, Rajkumar Sen and Biawsajit Chatterjee, Himalaya Publishing House, India.

[3] Ganti Subrahmanyam and B. Padmanarayan, 2011, "Sectoral Composition Bias in Money Demand: Some Evidence for India", The IUP Journal of Applied Economics, 10 (3), pp.56-63.

[4] Ganti Subrahmanyam, T. Sridhar and A. Debashis, 2014, "Perverse Liquidity Effect of Monetary Policy: Some Evidence for India", Macroeconomics and Finance in Emerging Market Economies (Routledge), 7(1) pp.61-82.

[5] Peach Richard, R Robert and L. Henry. M, 2013, "The Parts are more than the Whole: Separating Goods and Services to Predict Core Inflation, Current Issues in Economics and Finance (Federal Reserve Bank of New York) 19 (7)pp.1-8.

[6] Knox Lowell, C A. 1968, "Capacity Utilization and Production Function Estimation in Postwar American Manufacturing", the Quarterly Journal of Economics, 82(May), pp.219-239. 
[7] Ganti Subrahmanyam and J Ramesh, 2017," Can CRR, CAR and SLR Tools Perform Perversely?" Macroeconomics and Finance in Emerging Market Economies (Routledge), 10(2) pp.205-213.

[8] Ganti.et al., 2016, "GDP Structure Effects on Macro-Money Demand: Herfindahl Index Evidence for India", The IUP Journal of Applied Economics, 15(3), pp.31-36.
[9] GantiSubrahmanyam, 1997-98, "Kinks in the Empirical Money Demand Function for India", TheIndian Economic Journal: (Special Number in Monetary Economics), 46(July-september), pp.12-19.

[10] Ganti .Subrahmanyam and Cosimano, Thomas, F, 1979, "Money and Biased Technical Progress", Journal of Monetary Economics,5(October, USA), pp.497-504. 